\title{
Effect of mirabegron on cognitive function in elderly patients with overactive bladder: MoCA results from a phase 4 randomized, placebo-controlled study (PILLAR)
}

Tomas L. Griebling ${ }^{1 *}$, Noll L. Campbell ${ }^{2,3}$, Jeffrey Mangel ${ }^{4}$, David Staskin ${ }^{5}$, Sender Herschorn ${ }^{6}$, Dina Elsouda ${ }^{7}$ and Carol R. Schermer ${ }^{7}$

\begin{abstract}
Background: Antimuscarinics are often used for treatment of overactive bladder (OAB), but exposure to medications such as antimuscarinics that have anticholinergic properties has been linked to adverse cognitive effects. A phase 4 placebocontrolled study (PILLAR; NCT02216214) described the efficacy and safety of mirabegron, a $\beta_{3}$-adrenoreceptor agonist, for treatment of wet $O A B$ in patients aged $\geq 65$ years. This pre-planned analysis aimed to measure differences in cognitive function between mirabegron and placebo, using a rapid screening instrument for mild cognitive impairment: the Montreal Cognitive Assessment (MoCA).
\end{abstract}

Methods: Outpatients aged $\geq 65$ years with wet $O A B$ were randomized 1:1 to mirabegron or placebo, stratified by age $(<75 / \geq 75$ years). There were no exclusion criteria regarding cognitive status. Patients randomized to mirabegron initially received $25 \mathrm{mg} /$ day with an optional increase to $50 \mathrm{mg} /$ day after week $4 / 8$ based on patient/investigator discretion. The MoCA was administered at baseline and end of treatment (EoT, week 12). The study protocol was Independent Ethics Committee/Institutional Review Board-approved.

Results: Of the 887 randomized patients who received $\geq 1$ dose of study drug, $72.3 \%$ were female, $79.5 \%$ were white, and $28.1 \%$ were aged $\geq 75$ years. All patients had $\geq 1$ comorbidity and $94.3 \%$ were receiving $\geq 1$ concomitant medication. One third of patients had a history of psychiatric disorders, the most common being depression (17.2\%), insomnia (15.7\%), and anxiety (11.4\%). Baseline mean (standard error, SE) MoCA total scores were $26.9(0.1)$ and $26.8(0.1)$ in the mirabegron and placebo groups, respectively. Among patients with MoCA data available at baseline/EoT, 27.1\% (115/425) and 25.8\% (106/411) of mirabegron and placebo group patients, respectively, had impaired cognitive function at baseline (MoCA total score $<26$ ). There was no statistically significant change in adjusted mean (SE) MoCA total score from baseline to EOT in the mirabegron group $(-0.2[0.1])$ or the placebo group ( $-0.1[0.1])$.

Conclusions: Treatment with mirabegron for 12 weeks did not contribute to drug-related cognitive side effects in patients aged $\geq 65$ years, as measured by the MoCA. Furthermore, the pattern of change in cognition over time in an older $O A B$ trial population does not appear to differ from that of subjects receiving placebo.

Trial registration: NCT02216214 (prospectively registered August 13, 2014).

Keywords: Aged, Clinical trial, Phase 4, Cognition, Lower urinary tract symptoms, Urinary bladder, Overactive, Elderly, Geriatric

\footnotetext{
* Correspondence: tgriebling@kumc.edu

${ }^{1}$ Department of Urology and The Landon Center on Aging, University of

Kansas School of Medicine, Kansas City, KS, USA

Full list of author information is available at the end of the article
}

(c) The Author(s). 2020 Open Access This article is distributed under the terms of the Creative Commons Attribution 4.0 International License (http://creativecommons.org/licenses/by/4.0/), which permits unrestricted use, distribution, and reproduction in any medium, provided you give appropriate credit to the original author(s) and the source, provide a link to the Creative Commons license, and indicate if changes were made. The Creative Commons Public Domain Dedication waiver (http://creativecommons.org/publicdomain/zero/1.0/) applies to the data made available in this article, unless otherwise stated. 


\section{Background}

Overactive bladder $(\mathrm{OAB})$ is a symptom complex of storage lower urinary tract symptoms (LUTS) characterized by the presence of urgency. It affects all ages, but is increasingly prevalent as age increases [1-4]. According to the National Overactive Bladder Evaluation (NOBLE) study, prevalence of $\mathrm{OAB}$ in those $\geq 65$ years is around $30 \%$, twice as prevalent as in those $\leq 45$ years [2]. By 2025 , it is estimated that there will be 52 million adults in the USA with LUTS [5]. The older patient population with $\mathrm{OAB}$ has high levels of concomitant medication use and comorbidity, is more likely to experience falls and fractures, and is at increased risk of impairment of activities of daily living [6-8]. However, frail elderly patients with multiple comorbidities are often excluded from clinical trials [9-11].

Antimuscarinics are used to treat $\mathrm{OAB}$, however, the risk of anticholinergic adverse events (AEs) such as dry mouth and constipation increases with age [12]. Exposure to medications with anticholinergic properties has also been linked to adverse cognitive effects, in particular in patients $\geq 65$ years [13]. Furthermore, older people are particularly sensitive to anticholinergic effects as a result of significant age-related decrease in cholinergic neurons/receptors in the brain, reduction in hepatic and renal clearance of medications, and increase in bloodbrain barrier (BBB) permeability [14]. In addition, the older patient population is likely to be receiving polypharmacy including other drugs with anticholinergic activity (e.g. tricyclic antidepressants, bronchodilators, $\mathrm{ACE}$ inhibitors, and antipsychotics), potentially resulting in a problematic anticholinergic burden, with negative effects on cognitive performance [15]. As a result, the Beers criteria lists all antimuscarinic drugs used for the treatment of $\mathrm{OAB}$ as potentially inappropriate for firstline treatment in those $\geq 65$ years of age with dementia or cognitive impairment [16].

There are several screening instruments to detect dementia and cognitive impairment, including the MiniMental State Examination (MMSE) [17], the Geriatric Mental State Examination [18] and the Montreal Cognitive Assessment (MoCA) [19]. The 30-item MoCA, a brief cognitive screening tool for mild cognitive impairment (MCI), is recognized as a sensitive measure of cognitive function that can capture declines in cognition over repeated administrations. The MoCA is scaled from 1 to 30 , with higher MoCA scores indicating better cognitive function; a MoCA score $<26$ indicates impaired cognitive function [19]. The MoCA includes six cognitive domains, including visuospatial abilities; language; combined attention, concentration, and working memory; executive function; short-term memory recall; and orientation to time and place, although subsequent consensus has emerged that the total score is most meaningful. The MoCA was conceptualized as an improvement over the MMSE, which does not allow for discrimination between those with $\mathrm{MCI}$ and elderly adults with no cognitive impairment. The original context for the MoCA was as a clinical tool, serving frontline physicians in making an initial assessment of MCI.

Mirabegron is a $\beta_{3}$-adrenoreceptor agonist that represents an alternative $\mathrm{OAB}$ treatment to antimuscarinics, and potentially has a more favorable benefit-to-risk ratio in older patient populations [20-23]. The PILLAR study compared flexibly-dosed mirabegron versus placebo in community-dwelling elderly patients $\geq 65$ years with $\mathrm{OAB}$ and incontinence [24]. Statistically significant mean improvements in bladder diary parameters were observed for mirabegron versus placebo, and safety and tolerability were in line with the mirabegron safety profile. The PILLAR study is the first to use MoCA to detect potential cognitive decline related to $\mathrm{OAB}$ treatment and aimed to measure any differences in change from baseline of MoCA scores between mirabegron and placebo.

\section{Methods}

Full methods are described in the PILLAR primary paper [24], but, in brief, PILLAR was a phase 4, multicentre, 12week study in the US and Canada. Independent Ethics Committee/Institutional Review Board-approved written informed consent was obtained from all participants or their legally authorized representatives. This study adheres to CONSORT guidelines. Community-dwelling patients aged $\geq 65$ years with wet $\mathrm{OAB}$ ( $\geq 1$ incontinence episode and $\geq 3$ urgency episodes during the 3-day diary, plus an average of $\geq 8$ micturitions $/ 24 \mathrm{~h}$ ), were randomized in a 1:1 fashion to receive mirabegron or placebo. There were no specific exclusion criteria regarding cognitive status, although patients needed to be able to complete the micturition diaries and questionnaires. Patient-reported medical/surgical history was used to identify comorbidities. Patients who were randomized to mirabegron initially received $25 \mathrm{mg} /$ day, with an optional increase to $50 \mathrm{mg} /$ day after week $4 / 8$ based on patient/investigator discretion. The study was designed and powered to detect a difference on incontinence and micturition frequency between combined mirabegron and placebo groups, and was not powered to detect a difference in MoCA scores. Data are displayed as placebo versus total mirabegron and according to treatment group. The safety analysis set (SAF) included all randomized patients receiving at least 1 dose of study medication. AEs were recorded throughout the study until week 16 (4 weeks post end of treatment [EoT]). The MoCA was the sole safety endpoint for which inferential comparison was pre-specified in the PILLAR statistical analysis plan. Stratified rank analysis of covariance with change in score 
Table 1 Baseline characteristics (safety analysis set)

Female sex, $n(\%)$
Age, mean $\pm \mathrm{SD}$
Age $\geq 75$ years, $n(\%)$
BMl, kg/m², mean $\pm \mathrm{SD}$
Category, $n(\%)$
$<25$
$\geq 25-<30$
$\geq 30$

Ethnicity, $n$ (\%)

Not Hispanic or Latino
Hispanic or Latino
Unknown

Race, $n$ (\%)

White

Black or African American
Other
Country, $n$ (\%)
United States
Canada

Charlson Comorbidity Index score, mean \pm SD

History of psychiatric disorders

$\begin{array}{lll}\text { Depression } & 72(16.3) & 81(18.2) \\ \text { Insomnia } & 82(18.6) & 57(12.8) \\ \text { Anxiety } & 42(9.5) & 59(13.3) \\ \text { Sleep disorder } & 5(1.1) & 6(1.3) \\ \text { Attention deficit/hyperactivity } & 4(0.9) & 4(0.9) \\ \text { disorder } & & \\ \text { Libido decreased } & 4(0.9) & 4(0.9) \\ \text { Bipolar disorder } & 3(0.7) & 4(0.9) \\ \text { Nicotine dependence } & 5(1.1) & 1(0.2) \\ \text { Adjustment disorder with } & 2(0.5) & 1(0.2) \\ \text { depressed mood } & & \\ \text { Initial insomnia } & 0 & 2(0.4) \\ \text { Persistent depressive disorder } & 0 & 2(0.4) \\ \text { Stress } & 0 & 2(0.4) \\ \text { Major depression } & 1(0.2) & 1(0.2) \\ \text { Adjustment disorder } & 0 & 1(0.2) \\ \text { Alcoholism } & 0 & 1(0.2) \\ \text { Burnout syndrome } & 0 & 1(0.2) \\ \text { Depressed mood } & 0 & 1(0.2) \\ \text { Drug abuse } & 0 & 1(0.2) \\ \text { Drug dependence } & 1(0.2) \\ & 0 & \end{array}$

Table 1 Baseline characteristics (safety analysis set) (Continued)

\begin{tabular}{lll}
\hline & $\begin{array}{l}\text { Placebo } \\
(n=442)\end{array}$ & $\begin{array}{l}\text { Mirabegron Total } \\
(n=445)\end{array}$ \\
\hline Emotional disorder & 0 & $1(0.2)$ \\
Mood swings & 0 & $1(0.2)$ \\
Nervousness & 0 & $1(0.2)$ \\
Post-traumatic stress disorder & 0 & $1(0.2)$ \\
Premature ejaculation & 0 & $1(0.2)$ \\
Anxiety disorder & $1(0.2)$ & 0 \\
Claustrophobia & $1(0.2)$ & 0 \\
Obsessive-compulsive disorder & $1(0.2)$ & 0 \\
MoCA total score ${ }^{a}, n(\%)$ & & \\
Category, $n(\%)$ & & \\
$\quad$ Normal $(\geq 26)$ & $305(69.3)$ & $310(70.0)$ \\
Mild $(18-25)$ & $103(23.4)$ & $112(25.3)$ \\
Moderate (10-17) & $3(0.7)$ & $3(0.7)$ \\
Severe (<10) & 0 & 0 \\
Missing & $29(6.6)$ & $18(4.1)$ \\
\hline
\end{tabular}

Safety analysis set (SAF): all randomized subjects who received $\geq 1$ dose of study medication

MoCA Montreal Cognitive Assessment, SD standard deviation

${ }^{\mathrm{a}} N=440$ for placebo and 443 for mirabegron total

from baseline was the response variable, with treatment group and gender as fixed factors. An additional ANCOVA included treatment, gender, and MoCA score at baseline as covariates. The MoCA was conducted at baseline and EoT, week 12, by clinic staff trained in its administration, in either English or Canadian French. Information on education level was not collected directly; however, clinic staff were instructed to add 1 point for any participants with $\leq 12$ years education, as per the original MoCA scoring instructions [19]. Differences in change from baseline of MoCA scores between mirabegron and placebo were analyzed using a stratified ANCOVA model. As a complement to the pre-specified analyses, a post hoc analysis of relative risk was conducted to determine the relative risk of change in MoCA score by at least 4 points, which is deemed the minimum detectable change (MDC) [25]. Other post hoc analyses were change from baseline to EoT by baseline medical history of depression or antidepressant medication use, or by presence of $\geq 1$ strong anticholinergic concomitant medication.

\section{Results}

Baseline

Of the 2380 patients screened, 445 were randomized to mirabegron and 443 to placebo; one patient in the placebo group did not receive treatment (Table 1). Of the 887 randomized patients who received $\geq 1$ dose of study drug, overall $72.3 \%$ were female, $79.5 \%$ were white, and $28.1 \%$ 
Table 2 Concomitant non-OAB medications relevant to cognition during double-blind treatment period

\begin{tabular}{|c|c|c|}
\hline$n(\%)$ & $\begin{array}{l}\text { Placebo } \\
(n=442)\end{array}$ & $\begin{array}{l}\text { Mirabegron Total } \\
(n=445)\end{array}$ \\
\hline \multicolumn{3}{|l|}{ CONCOMITANT ANTIDEPRESSANTS } \\
\hline SSRIS & $54(12.2)$ & $53(11.9)$ \\
\hline Citalopram & $14(3.2)$ & $9(2.0)$ \\
\hline Sertraline & $11(2.5)$ & $4(0.9)$ \\
\hline Escitalopram oxalate & $5(1.1)$ & $8(1.8)$ \\
\hline Escitalopram & $5(1.1)$ & $7(1.6)$ \\
\hline Fluoxetine & $8(1.8)$ & $4(0.9)$ \\
\hline Citalopram hydrobromide & $3(0.7)$ & $6(1.3)$ \\
\hline Paroxetine & $1(0.2)$ & $6(1.3)$ \\
\hline Sertraline hydrochloride & $4(0.9)$ & $3(0.7)$ \\
\hline Fluoxetine hydrochloride & $3(0.7)$ & $3(0.7)$ \\
\hline Paroxetine hydrochloride & 0 & $3(0.7)$ \\
\hline Other antidepressants & $23(5.2)$ & $31(7.0)$ \\
\hline Trazodone & $13(2.9)$ & $17(3.8)$ \\
\hline Duloxetine & $3(0.7)$ & $4(0.9)$ \\
\hline Duloxetine hydrochloride & $4(0.9)$ & $2(0.4)$ \\
\hline Mirtazapine & $2(0.5)$ & $3(0.7)$ \\
\hline Trazodone hydrochloride & 0 & $3(0.7)$ \\
\hline Venlafaxine hydrochloride & $2(0.5)$ & $1(0.2)$ \\
\hline Desvenlafaxine succinate & 0 & $1(0.2)$ \\
\hline Nefazodone & 0 & $1(0.2)$ \\
\hline Oxitriptan & 0 & $1(0.2)$ \\
\hline Venlafaxine & $1(0.2)$ & 0 \\
\hline Vortioxetine & $1(0.2)$ & 0 \\
\hline $\begin{array}{l}\text { Non-selective monoamine reuptake } \\
\text { inhibitors }\end{array}$ & $7(1.6)$ & $9(2.0)$ \\
\hline Amitriptyline & $2(0.5)$ & $7(1.6)$ \\
\hline Doxepin & $1(0.2)$ & $1(0.2)$ \\
\hline Nortriptyline & $2(0.5)$ & 0 \\
\hline Amitriptyline hydrochloride & 0 & $1(0.2)$ \\
\hline Imipramine & $1(0.2)$ & 0 \\
\hline Nortriptyline hydrochloride & $1(0.2)$ & 0 \\
\hline $\begin{array}{l}\text { Diazepines, oxazepines, thiazepines } \\
\text { and oxepines }\end{array}$ & $3(0.7)$ & $1(0.2)$ \\
\hline Quetiapine fumarate & $3(0.7)$ & $1(0.2)$ \\
\hline Other antipsychotics & 0 & $2(0.4)$ \\
\hline Aripiprazole & 0 & $1(0.2)$ \\
\hline Risperidone & 0 & $1(0.2)$ \\
\hline \multicolumn{3}{|l|}{ CONCOMITANT ANTICHOLINERGICS } \\
\hline Antihistamines for systemic use & $38(8.6)$ & $41(9.2)$ \\
\hline Hydroxyzine & $2(0.5)$ & $2(0.4)$ \\
\hline Hydroxyzine hydrochloride & $1(0.2)$ & $1(0.2)$ \\
\hline
\end{tabular}

Table 2 Concomitant non-OAB medications relevant to cognition during double-blind treatment period (Continued)

\begin{tabular}{lll}
\hline$n(\%)$ & $\begin{array}{l}\text { Placebo } \\
(n=442)\end{array}$ & $\begin{array}{l}\text { Mirabegron Total } \\
(n=445)\end{array}$ \\
\hline Aminoalkyl ethers & $15(3.4)$ & $16(3.6)$ \\
Diphenhydramine hydrochloride & $10(2.3)$ & $11(2.5)$ \\
Diphenhydramine & $4(0.9)$ & $4(0.9)$ \\
Dimenhydrinate & $1(0.2)$ & $1(0.2)$ \\
Carbinoxamine maleate & 0 & $1(0.2)$ \\
Piperazine derivatives & $3(0.7)$ & $2(0.4)$ \\
Meclozine & $2(0.5)$ & $1(0.2)$ \\
Phenothiazine derivatives & $1(0.2)$ & $1(0.2)$ \\
Promethazine & $1(0.2)$ & 0 \\
Promethazine hydrochloride & 0 & $1(0.2)$ \\
Substituted alkylamines & 0 & $2(0.4)$ \\
Chlorphenamine maleate & 0 & $2(0.4)$ \\
Cough and cold preparations & $17(3.8)$ & $20(4.5)$ \\
Promethazine with codeine & 0 & $1(0.2)$ \\
Carbamic acid esters & $5(1.1)$ & $1(0.2)$ \\
Carisoprodol & $2(0.5)$ & $1(0.2)$ \\
Synthetic anticholinergics, esters with & 0 & $2(0.4)$ \\
tertiary amine groups & & $2(0.4)$ \\
Dicycloverine hydrochloride & 0 & . \\
\hline OAB overactive bladder, sSRls selective serotonin reuptake & inhibitors \\
& & 0
\end{tabular}

were aged $\geq 75$ years. In total, 226 patients received mirabegron $25 \mathrm{mg}$ and only $219 / 445$ patients (49.2\%) uptitrated to $50 \mathrm{mg}$. There were no meaningful differences in demographic characteristics at baseline between the total mirabegron group and the placebo group. All patients had $\geq 1$ comorbidity and $94.3 \%$ were receiving $\geq 1$ concomitant medication; those relevant to cognition are shown in Table 2. One third of patients in the SAF had a history of psychiatric disorders, the most common being depression (17.2\%), insomnia (15.7\%), and anxiety (11.4\%). Charlson Comorbidity Index scores (mean $\pm \mathrm{SD}$ ) were low: $2.3 \pm 1.2$ for both groups (Table 1).

Table 3 Change from baseline to EoT in MoCA test total score (SAF)

\begin{tabular}{lll}
\hline & Placebo & Mirabegron Total \\
\hline Baseline, mean (SE) ${ }^{\mathrm{a}}$ & $26.8(0.1)$ & $26.9(0.1)$ \\
EoT, mean (SE) & $27.0(0.1)$ & $26.9(0.1)$ \\
Adjusted change from baseline, mean (SE) & $-0.1(0.1)$ & $-0.2(0.1)$ \\
$95 \%$ two-sided Cl & $(-0.4,0.2)$ & $(-0.4,0.1)$ \\
p-value & & 0.471 \\
\hline
\end{tabular}

$\mathrm{Cl}$ confidence interval, EoT end of treatment, MoCA Montreal Cognitive Assessment, SAF safety analysis set, $S E$ standard error

${ }^{\mathrm{a}} N=440$ for placebo and 443 for mirabegron total

${ }^{\mathrm{b}} \mathrm{N}=413$ for placebo and 427 for mirabegron total 


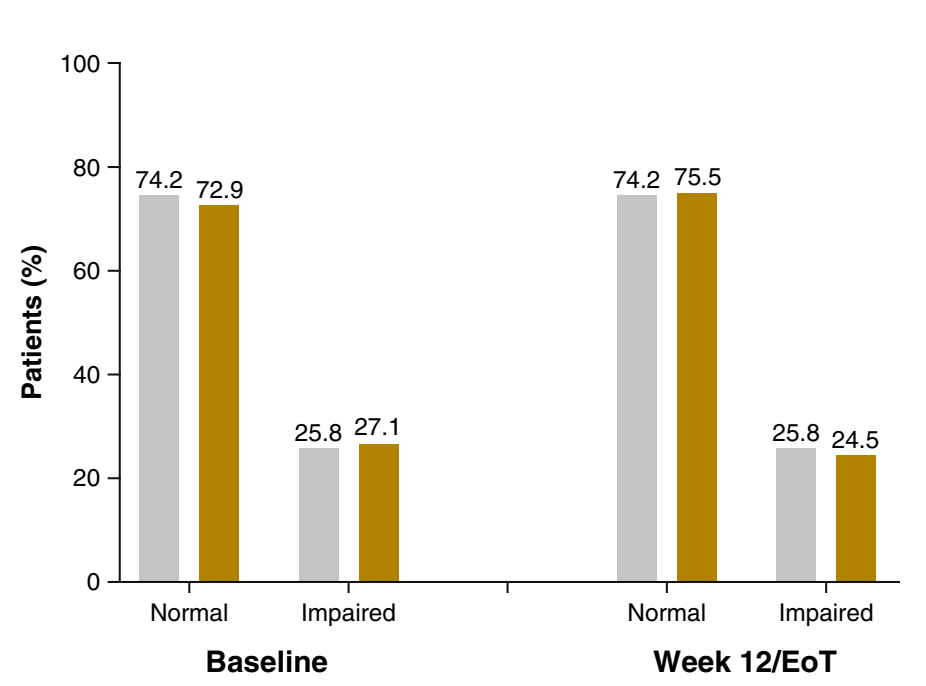

Baseline mean (standard error, SE) MoCA total scores were $26.9(0.1)$ and $26.8(0.1)$ in the mirabegron and placebo groups, respectively (Table 3 ). Among patients with MoCA data available at baseline/EoT, 27.1\% (115/425) and $25.8 \%$ (106/411) of mirabegron and placebo group patients, respectively, had impaired cognitive function (MoCA total score <26) at baseline (Fig. 1).

\section{End of treatment}

There were no changes in adjusted mean (SE) MoCA total score from baseline to EoT in the mirabegron group $(-0.2$ [0.1]) or the placebo group $(-0.1$ [0.1]) (Table 3). Changes in subscale scores are shown in Table 4 . The number of patients missing scores at EoT were 29 for placebo and 18 for the mirabegron total group. Of the 411 patients receiving placebo and 425 patients receiving mirabegron, 48 patients (24 in each group) had declines of MoCA score of $\geq 4$ points at week 12 . The distribution of score changes

Table 4 Change from baseline to EoT in MoCA subscale scores (SAF)

\begin{tabular}{lll}
\hline Change, mean (SD) & $\begin{array}{l}\text { Placebo } \\
(n=411)\end{array}$ & $\begin{array}{l}\text { Mirabegron Total } \\
(n=425)\end{array}$ \\
\hline Attention Points & $-0.0(0.9)$ & $-0.1(0.9)$ \\
Language Points & $0.0(0.7)$ & $0.0(0.7)$ \\
Naming Points & $-0.0(0.4)$ & $0.0(0.4)$ \\
Visuospatial/Executive Points & $0.0(1.0)$ & $-0.1(1.2)$ \\
Abstraction Points & $0.0(0.5)$ & $-0.0(0.5)$ \\
Delayed Recall Points & $0.2(1.4)$ & $0.2(1.3)$ \\
Orientation Points & $-0.0(0.4)$ & $-0.0(0.4)$
\end{tabular}

EOT end of treatment, MoCA Montreal Cognitive Assessment, SAF safety analysis set, $S D$ standard deviation are shown in Fig. 2. At week 12/EoT, 24.5\% (104/425) and $25.8 \%(106 / 411)$ of mirabegron and placebo patients, respectively, had impaired cognitive function (Fig. 1). Post hoc analyses showed mirabegron and placebo to be similar with respect to the likelihood of experiencing cognitive decline (Fig. 3), using the MDC for a community-living elder population found in the literature [25]. MoCA scores showed no differences in change from baseline to EoT by baseline medical history of depression or antidepressant medication use, or by presence of $\geq 1$ strong anticholinergic concomitant medication as recognized by the Anticholinergic Cognitive Burden scale [26] (Table 5).

Of note, over 300 study participants, or nearly $41 \%$, experienced an increase from one to nine points in MoCA score (Fig. 2). There were no differences between treatment and placebo groups in MoCA score improvements. The frequency of AEs that are typically seen with antimuscarinics was low for both mirabegron and placebo (Table 6).

\section{Discussion}

Treatment with mirabegron for 12 weeks had no adverse impact on cognitive function in patients aged $\geq 65$ years, as measured by the MoCA and compared with those randomized to placebo. Together with the efficacy demonstrated during the PILLAR study, these data suggest that mirabegron does not worsen cognition in older adults treated for $\mathrm{OAB}$ who are at risk of or concerned about cognitive impairment. Therefore, mirabegron represents a viable alternative for treatment of older patients with $\mathrm{OAB}$, especially for those on anticholinergic medications for other diseases. 


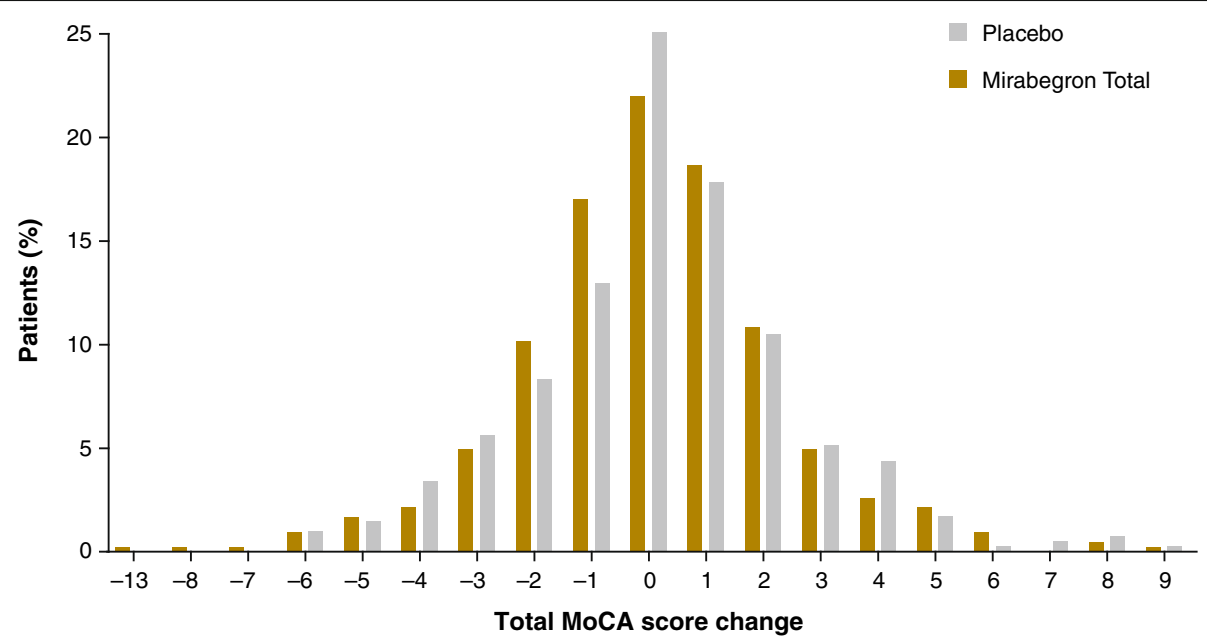

Fig. 2 Percentage of patients with indicated MoCA score change at week 12/EOT. EOT end of treatment, MoCA Montreal Cognitive Assessment

In comparison, a systematic review and several subsequent publications have found a strong link between cognitive impairment and anticholinergic potency of medications $[14,15,26,27]$. There appears to be a differential effect on cognition between antimuscarinics used in the treatment of $\mathrm{OAB}$, although there is substantial variability in scientific approaches such as duration of observation, outcome measures employed, and populations studied. Several studies have reported that oral oxybutynin has a significant negative effect on cognitive function in healthy adults $\geq 60$ years of age [28-31]. Cognitive impairment has also been reported with tolterodine at therapeutic doses in small numbers of cognitively intact [32-34] and cognitively impaired older people [35]. In separate studies, cumulative exposure to strong anticholinergics increased the odds of transitioning from normal cognition to $\mathrm{MCI}$ in adults $\geq 65$ years [36] and was associated with an increased risk for dementia and Alzheimer's disease [15]. Anticholinergics have also been suggested to reduce the likelihood of reverting to normal cognition among those with a diagnosis of MCI [36]. However, conflicting evidence in older people with dementia suggests that anticholinergics may not affect cognition in these individuals [27, 37, 38].

It is worth noting that oxybutynin and tolterodine made up the majority of $\mathrm{OAB}$ medication use in these prior reports. Other studies support the lack of cognitive effects for trospium in patients $\geq 75$ years [39-42]. Solifenacin at a dose of $10 \mathrm{mg}$ also had no detectable effect on cognition in healthy elderly volunteers $\geq 65$ years [29] or in those $\geq 75$ years with MCI [31]. With the exception of a case report of delirium following fesoterodine treatment in an 89-year-old man with renal failure [43], there do not appear to be reports of cognitive impairment with fesoterodine in patients $\geq 65$ years $[44,45]$, or with darifenacin in patients $\geq 60$ years [30] or $\geq 65$ years [46]. Newer, longer-acting antimuscarinics may therefore not be associated with cognitive effects; however, caution is warranted because of overall anticholinergic load.

As people aged $\geq 65$ years are frequently underrepresented in clinical trials, the results in the PILLAR study, which included a substantial proportion $\geq 75$ years, are clinically relevant. Patients in this study were community dwelling and relatively healthy, as shown by low

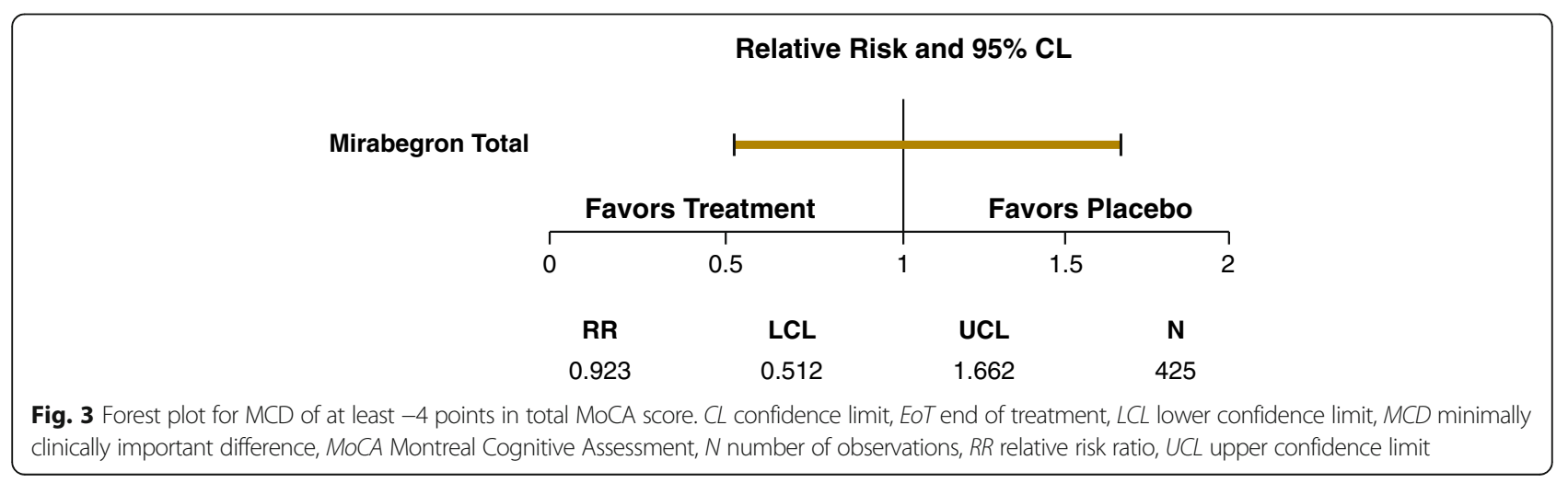


Table 5 MoCA scores for patients with/without use of antidepressant medication, depression diagnosis from medical history, and by use of strong anticholinergic burden concomitant medication

\begin{tabular}{|c|c|c|c|c|c|c|}
\hline & \multicolumn{3}{|l|}{ Placebo $(n=411)$} & \multicolumn{3}{|c|}{ Mirabegron Total $(n=425)$} \\
\hline & $\begin{array}{l}\text { Total score at BL, } \\
\text { mean (SD) }\end{array}$ & $\begin{array}{l}\text { Total score at EoT, } \\
\text { mean (SD) }\end{array}$ & $\begin{array}{l}\text { Change in Total } \\
\text { score, mean }\end{array}$ & $\begin{array}{l}\text { Total score at BL, } \\
\text { mean (SD) }\end{array}$ & $\begin{array}{l}\text { Total score at EoT, } \\
\text { mean (SD) }\end{array}$ & $\begin{array}{l}\text { Change in Total } \\
\text { score, mean }\end{array}$ \\
\hline \multicolumn{7}{|c|}{ Use of antidepressant medication ${ }^{a}$} \\
\hline No $(n=695)$ & $26.9(2.9)$ & $27.1(2.8)$ & 0.2 & $26.9(2.7)$ & $27.0(2.7)$ & 0.0 \\
\hline Yes $(n=141)$ & $26.6(2.6)$ & $26.9(2.4)$ & 0.3 & $26.5(3.0)$ & $26.6(2.8)$ & 0.2 \\
\hline \multicolumn{7}{|c|}{ Depression diagnosis from medical history ${ }^{\mathrm{b}}$} \\
\hline No $(n=683)$ & $26.8(2.9)$ & $27.0(2.7)$ & 0.2 & $27.0(2.5)$ & $27.0(2.7)$ & 0.0 \\
\hline Yes $(n=153)$ & $26.9(2.6)$ & $27.1(2.6)$ & 0.1 & $26.2(3.3)$ & $26.7(2.8)$ & 0.4 \\
\hline \multicolumn{7}{|c|}{ Use of anticholinergic burden concomitant medication ${ }^{c}$} \\
\hline No $(n=767)$ & $26.8(2.8)$ & $27.1(2.7)$ & 0.2 & $26.8(2.7)$ & $26.9(2.7)$ & 0.0 \\
\hline Yes $(n=69)$ & $26.6(3.5)$ & $26.6(3.1)$ & 0 & $27.0(2.9)$ & $27.4(2.4)$ & 0.4 \\
\hline
\end{tabular}

${ }^{\mathrm{a}} \mathrm{N}=345$ for placebo and 350 for mirabegron total for No, $N=66$ for placebo and 75 for mirabegron total for Yes

${ }^{\mathrm{b}} \mathrm{N}=341$ for placebo and 342 for mirabegron total for No, $N=70$ for placebo and 83 for mirabegron total for Yes

${ }^{\mathrm{C}} N=380$ for placebo and 387 for mirabegron total for No, $N=31$ for placebo and 38 for mirabegron total for Yes

baseline Charlson Comorbidity Index scores. However, the number of concomitant medications and comorbid conditions observed at baseline in this study are similar to those in the general older population [8].

The MoCA presents several advantages compared with the MMSE. For example, it includes more executive function and visuospatial items than the MMSE, thus the MoCA provides a more comprehensive assessment across cognitive domains. In addition, the MoCA 5word recall task is better at probing for subtle memory changes than the MMSE 3-word task [47]. The improvement in sensitivity in detecting cognitive decline compared with the MMSE has been clearly demonstrated, particularly in stroke studies $[48,49]$. Other advantages of the MoCA are that it can be administered in the clinical setting by a trained rater in $10 \mathrm{~min}$ (although training occurred for all sites it is worth noting that this study took place before mandatory MoCA training was introduced by the developers), without relying on specific expertise in neurology, psychiatry, or clinical psychology. The MoCA may therefore be useful to practitioners if they are concerned about cognitive decline in their patients due to an increased anticholinergic burden resulting from multiple medications [50].

A number of studies have assessed the ability of the MoCA to detect change in healthy and impaired populations. Feeney et al. provided a distribution-based estimate of change from a sample of communityliving people aged $\geq 55$ years in Ireland [25]. This study provided a calculation of the MDC, with the implication that an individual's score would need to change by $\geq 4$ points on the MoCA to be confident that the change was not due to chance or measurement error. In the current study, post hoc analyses utilizing the MDC showed that mirabegron and placebo were similar with respect to the likelihood of experiencing cognitive decline.

Although initially developed for capture of $\mathrm{MCI}$ in patients presenting with cognitive complaints due to Alzheimer's disease [19], the MoCA has also been used to assess cognitive decline associated with other conditions. These include stroke [51], acquired brain injury [52], Parkinson's disease [53, 54], chronic obstructive pulmonary disease [55], heart failure [56], complications of diabetes [57], chronic hemodialysis [58], and Huntington's disease [59]. The Huntington Study Group used the MoCA in a trial of dutetrabenazine for treatment of chorea in patients with Huntington's disease. They reported that there was no significant difference in the mean change on the total MoCA score between placebo and the treatment of interest across the 12 weeks of the

Table 6 Drug-related treatment-emergent adverse events $\geq 1 \%$ in either treatment group (SAF)

\begin{tabular}{lll}
\hline TEAEs, $n(\%)$ & $\begin{array}{l}\text { Placebo } \\
(n=442)\end{array}$ & $\begin{array}{l}\text { Mirabegron Total } \\
(n=445)\end{array}$ \\
\hline Drug-related TEAEs $^{\mathrm{a}}$ & $57(12.9)$ & $84(18.9)$ \\
$\quad$ Dry mouth & $7(1.6)$ & $6(1.3)$ \\
Nausea & $3(0.7)$ & $6(1.3)$ \\
Constipation & $4(0.9)$ & $3(0.7)$ \\
Diarrhea & $1(0.2)$ & $5(1.1)$ \\
Headache & $7(1.6)$ & $18(4.0)$ \\
Dizziness & $6(1.4)$ & $2(0.4)$ \\
Somnolence & $1(0.2)$ & $2(0.4)$ \\
Escherichia urinary tract infection & $7(1.6)$ & $9(2.0)$ \\
Fatigue & $10(2.3)$ & $7(1.6)$ \\
\hline
\end{tabular}

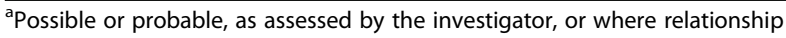
was missing

SAF safety analysis set, TEAEs treatment-emergent adverse events 
trial [59]. This outcome reflects the use of the MoCA in the current study.

The MoCA was developed specifically for detecting decrements in the performance of basic neurocognitive tasks, although it has also been used to track improvements. The current study supports the use of the MoCA for measuring decline in cognitive function as a side effect of $O A B$ treatment and also demonstrates the similarity in general cognitive function outcomes between mirabegron and placebo. While the MoCA has wellestablished utility as a screening tool for cognitive impairment, it is not a diagnostic test and provides incomplete measurement of the individual core cognitive domains. It should therefore not be viewed as a substitute for more in-depth neuropsychological assessment when domain-specific information is required [60].

Limitations of the current study include the short study duration and the use of the same version of the MoCA 12 weeks after first administration. This use of the same version is likely reflected in the $41 \%$ of patients who improved their MoCA score on subsequent administration (i.e. a training effect). In addition, the study enrolled patients with wet $\mathrm{OAB}$ based in the community, so the results are not representative of other elderly patient groups, such as those in nursing homes or hospitalized. Also, Charlson Comorbidity Index scores were very low at baseline, indicating that these communitydwelling patients were generally healthy and unlikely to be frail; thus these findings do not apply to all elderly individuals with $\mathrm{OAB}$.

\section{Conclusions}

Cognitive assessment over 12 weeks using the MoCA in the PILLAR study demonstrates that mirabegron treatment does not contribute to drug-related cognitive sideeffects. Furthermore, the pattern of change in cognition over the trial duration in an older OAB trial population does not appear to differ from that of subjects receiving placebo.

\section{Abbreviations}

AEs: Adverse events; BBB: Blood-brain barrier; EoT: End of treatment; LUTS: Lower urinary tract symptoms; MCl: Mild cognitive impairment; MDC: Minimum detectable change; MMSE: Mini-Mental State Examination; MoCA: Montreal Cognitive Assessment; NOBLE: National Overactive Bladder Evaluation; OAB: Overactive bladder

\section{Acknowledgments}

The authors would like to thank the PILLAR study investigators, and all patients and their family/legal representatives who took part in the study. Preliminary results of this research were presented previously at EAU in 2019 (https://doi. org/10.1016/S1569-9056(19)31134-0).

\section{Authors' contributions}

DE performed statistical analysis. TLG, NLC, JM, DS, SH, DE and CRS were involved in study design, analysis and interpretation of data and drafting the manuscript, and read and approved the final manuscript.

\section{Funding}

Astellas Pharma Global Development, Inc. initiated and funded the study and contributed to the design, analysis and interpretation of data and provided funding for medical writing. Medical writing support was provided by Sue Cooper, CMPP, of Envision Scientific Solutions.

\section{Availability of data and materials}

Access to anonymized individual participant-level data collected during the trial, in addition to supporting clinical documentation, is planned for trials conducted with approved product indications and formulations, as well as compounds terminated during development. Conditions and exceptions are described under the Sponsor Specific Details for Astellas on wnw.clinicalstudydatarequest.com. Study-related supporting documentation is redacted and provided if available, such as the protocol and amendments, statistical analysis plan and clinical study report. Access to participant-level data is offered to researchers after publication of the primary manuscript (if applicable) and is available as long as Astellas has legal authority to provide the data. Researchers must submit a proposal to conduct a scientifically relevant analysis of the study data. The research proposal is reviewed by an Independent Research Panel. If the proposal is approved, access to the study data is provided in a secure data sharing environment after receipt of a signed Data Sharing Agreement.

Ethics approval and consent to participate

The study protocol was reviewed by an Independent Ethics Committee/ Institutional Review Board for the study sites. Approval for the study protocol was obtained from the relevant competent authority prior to study initiation. Institutional Review Board/Independent Ethics Committee-approved written informed consent was obtained from all participants or their legally authorized representative prior to any study-related procedures.

\section{Consent for publication}

Not applicable as no individual data are reported, all data has been anonymized and participants are not identifiable.

\section{Competing interests}

TLG is a consultant for Astellas, and has received grants from the National Institute on Aging and the National Institutes of Health. NLC is a consultant for Astellas. JM has received grants from Astellas. DS has received grants and personal fees for services as an investigator, consultant, and speaker for Astellas. SH has received grants from Allergan, Astellas, Ipsen, and Ixaltis, and personal fees from Allergan, Astellas, and Pfizer. DE and CRS are employees of Astellas Pharma Global Development, Inc.

\section{Author details}

${ }^{1}$ Department of Urology and The Landon Center on Aging, University of Kansas School of Medicine, Kansas City, KS, USA. ${ }^{2}$ College of Pharmacy, Purdue University, Lafayette, IN, USA. ${ }^{3}$ Center for Aging Research, Indiana University, Indianapolis, IN, USA. ${ }^{4}$ Division of Urogynecology and Pelvic Reconstructive Surgery, MetroHealth Medical Center, Cleveland, OH, USA. ${ }^{5}$ Division of Urology, St Elizabeth's Medical Center, Boston, MA, USA. ${ }^{6}$ Division of Urology, Sunnybrook Health Sciences Centre, University of Toronto, Toronto, Ontario, Canada. ${ }^{7}$ Medical Affairs, Astellas Pharma Global Development, Inc., Northbrook, IL, USA.

Received: 8 October 2019 Accepted: 14 February 2020

Published online: 18 March 2020

\section{References}

1. Milsom I, Stewart W, Thüroff J. The prevalence of overactive bladder. Am J Manag Care. 2000;6(11 Suppl):S565-73.

2. Stewart WF, Van Rooyen JB, Cundiff GW, Abrams P, Herzog AR, Corey R, et al. Prevalence and burden of overactive bladder in the United States. World J Urol. 2003;20(6):327-36.

3. Coyne KS, Sexton CC, Thompson CL, Milsom I, Irwin D, Kopp ZS, et al. The prevalence of lower urinary tract symptoms (LUTS) in the USA, the UK and Sweden: results from the Epidemiology of LUTS (EpiLUTS) study. BJU Int. 2009;104(3):352-60.

4. Irwin DE, Milsom I, Hunskaar S, Reilly K, Kopp Z, Herschorn S, et al. Population-based survey of urinary incontinence, overactive bladder, and other lower urinary tract symptoms in five countries: results of the EPIC study. Eur Urol. 2006;50(6):1306-15. 
5. Litman HJ, McKinlay JB. The future magnitude of urological symptoms in the USA: projections using the Boston Area Community Health survey. BJU Int. 2007;100(4):820-5.

6. Zarowitz BJ, Allen C, O'Shea T, Tangalos E, Berner T, Ouslander JG. Clinical burden and nonpharmacologic management of nursing facility residents with overactive bladder and/or urinary incontinence. Consult Pharm. 2015; 30(9):533-42.

7. Soliman Y, Meyer R, Baum N. Falls in the elderly secondary to urinary symptoms. Rev Urol. 2016;18(1):28-32.

8. Ganz ML, Liu J, Zou KH, Bhagnani T, Luo X. Real-world characteristics of elderly patients with overactive bladder in the United States. Curr Med Res Opin. 2016;32(12):1997-2005.

9. Wolff GF, Kuchel GA, Smith PP. Overactive bladder in the vulnerable elderly. Res Rep Urol. 2014;6:131-8.

10. Kistler KD, Xu Y, Zou KH, Ntanios F, Chapman DS, Luo X. Systematic literature review of clinical trials evaluating pharmacotherapy for overactive bladder in elderly patients: an assessment of trial quality. Neurourol Urodyn. 2018;37(1):54-66.

11. DuBeau CE, Kuchel GA, Johnson II T, Palmer MH, Wagg A. Incontinence in the frail elderly: report from the 4th international consultation on incontinence. Neurourol Urodyn. 2010;29(1):165-78.

12. Fortin M-P, Rouch I, Dauphinot V, Gédéon C, Genthon S, Bonnefoy M, et al. Effects of anticholinergic drugs on verbal episodic memory function in the elderly: a retrospective, cross-sectional study. Drugs Aging. 2011;28(3):195-204.

13. Ancelin ML, Artero S, Portet F, Dupuy A-M, Touchon J, Ritchie K. Nondegenerative mild cognitive impairment in elderly people and use of anticholinergic drugs: longitudinal cohort study. BMJ. 2006;332:455.

14. Campbell N, Boustani M, Limbil T, Ott C, Fox C, Maidment I, et al. The cognitive impact of anticholinergics: A clinical review. Clin Interv Aging. 2009:4:225-33

15. Gray SL, Anderson ML, Dublin S, Hanlon JT, Hubbard R, Walker R, et al. Cumulative use of strong anticholinergics and incident dementia: a prospective cohort study. JAMA Intern Med. 2015;175(3):401-7.

16. By the American Geriatrics Society 2015 Beers Criteria Update Expert Panel. American Geriatrics Society 2015 updated Beers Criteria for potentially inappropriate medication use in older adults. J Am Geriatr Soc. 2015;63(11): 2227-46.

17. Folstein MF, Folstein SE, McHugh PR. "Mini-mental state": A practical method for grading the cognitive state of patients for the clinician. J Psychiatr Res. 1975;12(3):189-98.

18. Copeland JRM, Dewey ME, Henderson AS, Kay DWK, Neal CD, Harrison MAM, et al. The Geriatric Mental State (GMS) used in the community: replication studies of the computerized diagnosis AGECAT. Psychol Med. 1988;18(1):219-23.

19. Nasreddine ZS, Phillips NA, Bédirian V, Charbonneau S, Whitehead V, Collin I, et al. The Montreal Cognitive Assessment, MoCA: a brief screening tool for mild cognitive impairment. J Am Geriatr Soc. 2005;53(4):695-9.

20. Drake MJ, MacDiarmid S, Chapple CR, Esen A, Athanasiou S, Cambronero Santos J, et al. Cardiovascular safety in refractory incontinent patients with overactive bladder receiving add-on mirabegron therapy to solifenacin (BESIDE). Int J Clin Pract. 2017;71(5):e12944.

21. Yoshida M, Nozawa Y, Kato D, Tabuchi H, Kuroishi K. Safety and effectiveness of mirabegron in patients with overactive bladder aged $\geq 75$ years: analysis of a Japanese post-marketing study. Low Urin Tract Symptoms. 2019;11(1):30-8.

22. Wagg A, Cardozo L, Nitti WW, Castro-Diaz D, Auerbach S, Blauwet MB, et al. The efficacy and tolerability of the $\beta 3$-adrenoceptor agonist mirabegron for the treatment of symptoms of overactive bladder in older patients. Age Ageing. 2014;43(5):666-75.

23. Wagg A, Nitti WW, Kelleher C, Castro-Diaz D, Siddiqui E, Berner T. Oral pharmacotherapy for overactive bladder in older patients: mirabegron as a potential alternative to antimuscarinics. Curr Med Res Opin. 2016;32(4):621-38.

24. Wagg A, Staskin D, Engel E, Herschorn S, Kristy RM, Schermer CR. Efficacy, safety, and tolerability of mirabegron in patients aged $\geq 65$ yr with overactive bladder wet: a phase IV, double-blind, randomised, placebocontrolled study (PILLAR). Eur Urol. 2020;77(2):211-20.

25. Feeney J, Savva GM, O'Regan C, King-Kallimanis B, Cronin H, Kenny RA. Measurement error, reliability, and minimum detectable change in the MiniMental State Examination, Montreal Cognitive Assessment, and Color Trails Test among community living middle-aged and older adults. J Alzheimers Dis. 2016;53(3):1107-14.
26. Boustani M, Campbell N, Munger S, Maidment I, Fox C. Impact of anticholinergics on the aging brain: a review and practical application. Aging Health. 2008:4(3):311-20.

27. Fox C, Richardson K, Maidment ID, Savva GM, Matthews FE, Smithard D, et al. Anticholinergic medication use and cognitive impairment in the older population: the Medical Research Council cognitive function and ageing study. J Am Geriatr Soc. 2011;59(8):1477-83.

28. Katz IR, Sands LP, Bilker W, DiFilippo S, Boyce A, D'Angelo K. Identification of medications that cause cognitive impairment in older people: the case of oxybutynin chloride. J Am Geriatr Soc. 1998;46(1):8-13.

29. Wesnes KA, Edgar C, Tretter RN, Bolodeoku J. Exploratory pilot study assessing the risk of cognitive impairment or sedation in the elderly following single doses of solifenacin 10 mg. Expert Opin Drug Saf. 2009;8(6):615-26.

30. Kay G, Crook T, Rekeda L, Lima R, Ebinger U, Arguinzoniz M, et al. Differential effects of the antimuscarinic agents darifenacin and oxybutynin ER on memory in older subjects. Eur Urol. 2006;50(2):317-26.

31. Wagg A, Dale M, Tretter R, Stow B, Compion G. Randomised, multicentre, placebo-controlled, double-blind crossover study investigating the effect of solifenacin and oxybutynin in elderly people with mild cognitive impairment: the SENIOR study. Eur Urol. 2013;64(1):74-81.

32. Tsao JW, Heilman KM. Transient memory impairment and hallucinations associated with tolterodine use. N Engl J Med. 2003;349(23):2274-5.

33. Salvatore S, Serati M, Cardozo L, Uccella S, Bolis P. Cognitive dysfunction with tolterodine use. Am J Obstet Gynecol. 2007;197(2):e8.

34. Womack KB, Heilman KM. Tolterodine and memory: dry but forgetful. Arch Neurol. 2003;60(5):771-3.

35. Jewart RD, Green J, Lu C-J, Cellar J, Tune LE. Cognitive, behavioral, and physiological changes in Alzheimer disease patients as a function of incontinence medications. Am J Geriatr Psychiatry. 2005;13(4):324-8.

36. Campbell NL, Lane KA, Gao S, Boustani MA, Unverzagt F. Anticholinergics influence transition from normal cognition to mild cognitive impairment in older adults in primary care. Pharmacotherapy. 2018;38(5):511-9.

37. Lackner TE, Wyman JF, McCarthy TC, Monigold M, Davey C. Randomized, placebo-controlled trial of the cognitive effect, safety, and tolerability of oral extended-release oxybutynin in cognitively impaired nursing home residents with urge urinary incontinence. J Am Geriatr Soc. 2008;56(5):862-70.

38. Sink KM, Thomas J 3rd, Xu H, Craig B, Kritchevsky S, Sands LP. Dual use of bladder anticholinergics and cholinesterase inhibitors: long-term functional and cognitive outcomes. J Am Geriatr Soc. 2008;56(5):847-53.

39. Chancellor M, Boone T. Anticholinergics for overactive bladder therapy: central nervous system effects. CNS Neurosci Ther. 2012;18(2):167-74.

40. Staskin D, Kay G, Tannenbaum C, Goldman HB, Bhashi K, Ling J, et al. Trospium chloride is undetectable in the older human central nervous system. J Am Geriatr Soc. 2010;58(8):1618-9.

41. Geller EJ, Dumond JB, Bowling JM, Khandelwal CM, Wu JM, BusbyWhitehead J, et al. Effect of trospium chloride on cognitive function in women aged 50 and older: a randomized trial. Female Pelvic Med Reconstr Surg. 2017;23(2):118-23.

42. Staskin D, Kay G, Tannenbaum C, Goldman HB, Bhashi K, Ling J, et al. Trospium chloride has no effect on memory testing and is assay undetectable in the central nervous system of older patients with overactive bladder. Int J Clin Pract. 2010;64(9):1294-300.

43. Charbonneau JM, Bisset R, Nguyen PV-Q. Delirium following fesoterodine treatment for urgency incontinence in an 89-year old man. Can Urol Assoc J. 2016;10(7-8):E261-E3.

44. DuBeau CE, Kraus SR, Griebling TL, Newman DK, Wyman JF, Johnson TM 2nd, et al. Effect of fesoterodine in vulnerable elderly subjects with urgency incontinence: a double-blind, placebo controlled trial. J Urol. 2014;191(2): 395-404.

45. Kay GG, Maruff P, Scholfield D, Malhotra B, Whelan L, Darekar A, et al. Evaluation of cognitive function in healthy older subjects treated with fesoterodine. Postgrad Med. 2012;124(3):7-15.

46. Lipton RB, Kolodner K, Wesnes K. Assessment of cognitive function of the elderly population: effects of darifenacin. J Urol. 2005;173(2):493-8.

47. Lam B, Middleton LE, Masellis M, Stuss DT, Harry RD, Kiss A, et al. Criterion and convergent validity of the Montreal cognitive assessment with screening and standardized neuropsychological testing. J Am Geriatr Soc. 2013;61(12):2181-5.

48. Koski L. Validity and applications of the Montreal cognitive assessment for the assessment of vascular cognitive impairment. Cerebrovasc Dis. 2013; 36(1):6-18. 
49. Lees R, Selvarajah J, Fenton C, Pendlebury ST, Langhorne P, Stott DJ, et al. Test accuracy of cognitive screening tests for diagnosis of dementia and multidomain cognitive impairment in stroke. Stroke. 2014;45(10):3008-18.

50. Yoshida M, Kato D, Nishimura T, Van Schyndle J, Uno S, Kimura T. Anticholinergic burden in the Japanese elderly population: Use of antimuscarinic medications for overactive bladder patients. Int J Urol. 2018; 25(10):855-62

51. Burton L, Tyson SF. Screening for cognitive impairment after stroke: a systematic review of psychometric properties and clinical utility. J Rehabil Med. 2015;47(3):193-203.

52. Lim PA, McLean AM, Kilpatrick C, DeForge D, Iverson GL, Silverberg ND. Temporal stability and responsiveness of the Montreal Cognitive Assessment following acquired brain injury. Brain Inj. 2016;30(1):29-35.

53. Biundo R, Weis L, Bostantjopoulou S, Stefanova E, Falup-Pecurariu C, Kramberger MG, et al. MMSE and MoCA in Parkinson's disease and dementia with Lewy bodies: a multicenter 1-year follow-up study. J Neural Transm (Vienna). 2016;123(4):431-8.

54. Fiorenzato E, Weis L, Falup-Pecurariu C, Diaconu S, Siri C, Reali E, et al. Montreal Cognitive Assessment (MoCA) and Mini-Mental State Examination (MMSE) performance in progressive supranuclear palsy and multiple system atrophy. J Neural Transm (Vienna). 2016;123(12):1435-42.

55. Villeneuve S, Pepin V, Rahayel S, Bertrand J-A, de Lorimier M, Rizk A, et al. Mild cognitive impairment in moderate to severe COPD: a preliminary study. Chest. 2012;142(6):1516-23.

56. Cameron J, Worrall-Carter L, Page K, Baker SS, Ski CF. Screening for mild cognitive impairment in patients with heart failure: Montreal Cognitive Assessment versus Mini Mental State Exam. Eur J Cardiovasc Nurs. 2013; 12(3):252-60.

57. Oğurel T, Oğurel R, Özer MA, Türkel Y, Dağ E, Örnek K. Mini-mental state exam versus Montreal Cognitive Assessment in patients with diabetic retinopathy. Niger J Clin Pract. 2015;18(6):786-9.

58. Tiffin-Richards FE, Costa AS, Holschbach B, Frank RD, Vassiliadou A, Krüger T, et al. The Montreal Cognitive Assessment (MoCA) - a sensitive screening instrument for detecting cognitive impairment in chronic hemodialysis patients. PLoS One. 2014;9(10):e106700.

59. Huntington Study Group. Effect of deutetrabenazine on chorea among patients with Huntington disease: a randomized clinical trial. JAMA. 2016; 316(1):40-50.

60. Coen RF, Robertson DA, Kenny RA, King-Kallimanis BL. Strengths and limitations of the MoCA for assessing cognitive functioning: findings from a large representative sample of Irish older adults. J Geriatr Psychiatry Neurol. 2016;29(1):18-24.

\section{Publisher's Note}

Springer Nature remains neutral with regard to jurisdictional claims in published maps and institutional affiliations.

Ready to submit your research? Choose BMC and benefit from:

- fast, convenient online submission

- thorough peer review by experienced researchers in your field

- rapid publication on acceptance

- support for research data, including large and complex data types

- gold Open Access which fosters wider collaboration and increased citations

- maximum visibility for your research: over $100 \mathrm{M}$ website views per year

At BMC, research is always in progress.

Learn more biomedcentral.com/submissions 